Article

\title{
Vitamin D Level and Risk of Community-Acquired Pneumonia and Sepsis
}

\author{
Anna J. Jovanovich ${ }^{1}$, Adit A. Ginde ${ }^{2}$, John Holmen ${ }^{3}$, Kristen Jablonski ${ }^{1}$, Rebecca L. Allyn ${ }^{4}$, \\ Jessica Kendrick ${ }^{1,4}$ and Michel Chonchol ${ }^{1, *}$
}

1 Division of Renal Diseases and Hypertension, University of Colorado Denver, Denver, CO 80045 USA; E-Mails: Anna.Jovanovich@ucdenver.edu (A.J.J.); Kristen.Nowak@ucdenver.edu (K.J.); Jessica.Kendrick@ucdenver.edu (J.K.)

2 Department of Emergency Medicine, University of Colorado Denver, Denver, CO 80045 USA; E-Mail: Adit.Ginde@ucdenver.edu

3 Intermountain Healthcare, Salt Lake City, UT 84157, USA; E-Mail: John.Holmen@imail.org

4 Denver Health Medical Center, Denver, CO 80204, USA; E-Mail: Rebecca.Allyn@ucdenver.edu

* Author to whom correspondence should be addressed; E-Mail: Michel.Chonchol@ucdenver.edu; Tel.: +1-303-724-7796.

Received: 16 April 2014; in revised form: 14 May 2014 / Accepted: 23 May 2014 /

Published: 10 June 2014

\begin{abstract}
Previous research has reported reduced serum 25-hydroxyvitamin D (25(OH)D) levels is associated with acute infectious illness. The relationship between vitamin D status, measured prior to acute infectious illness, with risk of community-acquired pneumonia (CAP) and sepsis has not been examined. Community-living individuals hospitalized with CAP or sepsis were age-, sex-, race-, and season-matched with controls. ICD-9 codes identified CAP and sepsis; chest radiograph confirmed CAP. Serum 25(OH)D levels were measured up to 15 months prior to hospitalization. Regression models adjusted for diabetes, renal disease, and peripheral vascular disease evaluated the association of $25(\mathrm{OH}) \mathrm{D}$ levels with CAP or sepsis risk. A total of $132 \mathrm{CAP}$ patients and controls were $60 \pm 17$ years, $71 \%$ female, and $86 \%$ Caucasian. The $25(\mathrm{OH}) \mathrm{D}$ levels $<37 \mathrm{nmol} / \mathrm{L}$ (adjusted odds ratio (OR) $2.57,95 \%$ CI 1.08-6.08) were strongly associated with increased odds of CAP hospitalization. A total of 422 sepsis patients and controls were $65 \pm 14$ years, $59 \%$ female, and 91\% Caucasian. The 25(OH)D levels $<37 \mathrm{nmol} / \mathrm{L}$ (adjusted OR 1.75, 95\% CI 1.11-2.77) were associated with increased odds of sepsis hospitalization. Vitamin D status was inversely associated with risk of CAP and sepsis hospitalization in a
\end{abstract}


community-living adult population. Further clinical trials are needed to evaluate whether vitamin D supplementation can reduce risk of infections, including CAP and sepsis.

Keywords: vitamin D deficiency; sepsis; community-acquired pneumonia; infection; epidemiology

\section{Introduction}

Relatively little progress has been made in improving mortality associated with community-acquired pneumonia (CAP) [1] which is a leading cause of death in the United States [2]. Likewise, the incidence of sepsis continues to rise, the population-adjusted incidence of sepsis increased $8.7 \%$ per year between 1979 and 2000 [3]. While mortality associated with sepsis has improved [3], it remains a substantial cause of death in the United States [2].

The major circulating form of vitamin D, 25-hydroxyvitamin D $(25(\mathrm{OH}) \mathrm{D})$, and its active form, 1,25-dihydroxyvitamin $\mathrm{D}\left(1,25(\mathrm{OH})_{2} \mathrm{D}\right)$, were originally recognized as important endocrine hormones in calcium homeostasis and bone health. However, studies over the past twenty years suggest a broader role of $25(\mathrm{OH}) \mathrm{D}$ in endothelial function, cell proliferation, and immunity. The vitamin $\mathrm{D}$ receptor (VDR) is essentially ubiquitous, including immune cells. It responds to $1,25(\mathrm{OH})_{2} \mathrm{D}[4,5]$ and regulates antimicrobial peptides cathelicidin and beta-defensing [5]. Furthermore, $25(\mathrm{OH}) \mathrm{D}$ deficiency is common; $32 \%$ of the U.S. population have $25(\mathrm{OH}) \mathrm{D}$ levels $<50 \mathrm{nmol} / \mathrm{L}$ and $77 \%$ have levels $<75 \mathrm{nmol} / \mathrm{L}[6]$. Large epidemiological studies have shown an association between $25(\mathrm{OH}) \mathrm{D}$ deficiency and chronic diseases [7] including diabetes [8], renal disease [9], and peripheral vascular disease [10].

Lower serum 25(OH)D levels are associated with increased risk of upper respiratory tract infection [11-13]. When measured during hospital admission for acute illness, 25(OH)D deficiency is associated with increased risk of mortality in patients with CAP [14], more severe sepsis [15], and mortality in septic patients [16]. Most studies linking infection risk with 25(OH)D levels measure $25(\mathrm{OH}) \mathrm{D}$ during acute illness, which may not reflect pre-illness $25(\mathrm{OH}) \mathrm{D}$ status. There are no data assessing existing $25(\mathrm{OH}) \mathrm{D}$ deficiency with risk of hospital admission for CAP or sepsis. In this case-control study of community-living adults, serum $25(\mathrm{OH}) \mathrm{D}$ levels and the risk of hospital admission for CAP and sepsis was evaluated.

\section{Experimental Section}

\subsection{Data Source}

A retrospective matched cohort study was performed using the Intermountain Healthcare Enterprise Data Warehouse, which incorporates comprehensive electronic health and administrative data for over 10 years [17]. Intermountain Healthcare is a non-profit organization with 22 hospitals and over 150 outpatient clinics that serves the states of Utah and southeastern Idaho. The latitude of the hospitals and outpatient clinics is approximately $40^{\circ} \mathrm{N}$. Facilities range from major adult tertiary-level care centers to small clinics and hospitals that are the only source of care in rural communities. 
There were 160,979 admissions from 2008 to 2010 [17]. The institutional review board at Intermountain Healthcare System and University of Colorado Denver approved the project.

\subsection{Cohort Definition}

Case and control selection occurred between 1 January 2008 and 31 December 2010. CAP cases were identified through ICD-9 codes (480-488) and confirmed with chest radiograph. There were 187,132 CAP admissions of which 43,460 had discharge ICD-9 codes indicating pneumonia. Of these, 11,455 had chest radiography confirming pneumonia. 4352 Sepsis cases were identified through ICD-9 codes $(995.91,995.92)$. Controls were randomly selected from a pool of 62,757 adult patients without a CAP or sepsis diagnosis admitted within the same time period and matched 1:1 with cases by age, sex, race, and season of $25(\mathrm{OH}) \mathrm{D}$ measurement. Cases and control had to have a serum $25(\mathrm{OH})$ level in the electronic medical record 3-15 months prior to admission; therefore, only 132 and 422 patients were included in the final CAP and sepsis analyses, respectively. These time points were chosen arbitrarily to assess the relationship between pre-infection serum $25(\mathrm{OH}) \mathrm{D}$ levels and infectious episodes.

\subsection{5(OH) D Measurements}

Serum 25(OH)D level were measured in all participants using an INCSTAR 25(OH)D two step assay procedure with a coefficient of variation of less than $10 \%$. The first step in the procedure involves the rapid extraction of $25(\mathrm{OH}) \mathrm{D}$ from the serum using acetonitrile. Following extraction, the treated sample is assayed by using an equilibrium radioimmunoassay procedure. This method is based on an antibody with specificity to $25(\mathrm{OH}) \mathrm{D}$. The sample, antibody, and tracer are incubated at $20-25{ }^{\circ} \mathrm{C}$ for ninety minutes. A second antibody-precipitating complex is used to achieve phase separation. The radioimmunoassay method tends to overestimate the level of $25(\mathrm{OH}) \mathrm{D}$ because the antibody recognizes all forms of dihydroxy-vitamin D and D steroids.

\subsection{Statistical Analysis}

The associations of serum 25(OH)D levels with CAP or sepsis admission were evaluated separately. The $\chi^{2}$ Test of Independence tested the distribution of categorical variables and the Wilcoxon Rank Sum tested for differences in 25(OH)D levels among cases and controls. Cox logistic regression was performed using log-transformed $25(\mathrm{OH}) \mathrm{D}$ as a continuous variable and non-transformed $25(\mathrm{OH}) \mathrm{D}$ as a categorical variable $(<75 \mathrm{nmol} / \mathrm{L} v s . \geq 75 \mathrm{nmol} / \mathrm{L},<50 \mathrm{nmol} / \mathrm{L} v s . \geq 50 \mathrm{nmol} / \mathrm{L}$, and $<37 \mathrm{nmol} / \mathrm{L} v s . \geq 37 \mathrm{nmol} / \mathrm{L}$ ). These thresholds were chosen using established definitions of 25(OH)D deficiency/insufficiency [18,19]. Models adjusted for diabetes, renal disease, and peripheral vascular disease, which were chosen as confounding variables on the basis of previous studies [20,21] and obtained from the Charlson Comorbidity Index score. Two-tailed values of $p<0.05$ were considered statistically significant. 


\section{Results}

\subsection{Community-Acquired Pneumonia}

The demographic and clinical characteristics of the 66 cases and 66 controls for the CAP cohort are described in Table 1 . The mean (SD) age of the participants was $60 \pm 17$ years, $71 \%$ were female, and $86 \%$ were Caucasian. There was no statistically significant difference in median [IQR] 25(OH)D levels in controls $v s$. cases $(79.3[71.1-88.1] v s .70 .1[62.2-79.6] \mathrm{nmol} / \mathrm{L}, p=0.33)$. Renal disease was more prevalent in cases than controls $(31.8 \%$ vs. $10.6 \%, p=0.003)$. Serum $25(\mathrm{OH}) \mathrm{D}$ levels were recorded in 28 cases 3-5 months prior, in 18 cases 6-11 months prior, in 10 cases each 9-11 and 12-15 months prior to admission.

Table 1. Baseline characteristics for community-acquired pneumonia and sepsis cases and matched controls.

\begin{tabular}{|c|c|c|}
\hline & Case & Control \\
\hline \multicolumn{3}{|l|}{ Number } \\
\hline CAP & 66 & 66 \\
\hline Sepsis & 211 & 211 \\
\hline \multicolumn{3}{|c|}{ Age in years } \\
\hline CAP & $60 \pm 17$ & $60 \pm 17$ \\
\hline Sepsis & $65 \pm 14$ & $65 \pm 14$ \\
\hline \multicolumn{3}{|l|}{ Females } \\
\hline CAP & 47 & 47 \\
\hline Sepsis & 125 & 125 \\
\hline \multicolumn{3}{|c|}{ Race-White } \\
\hline CAP & 57 & 57 \\
\hline Sepsis & 189 & 189 \\
\hline \multicolumn{3}{|c|}{ Race-Hispanic } \\
\hline CAP & 6 & 6 \\
\hline Sepsis & 13 & 13 \\
\hline \multicolumn{3}{|c|}{ Race-Other } \\
\hline CAP & 3 & 3 \\
\hline Sepsis & 5 & 5 \\
\hline \multicolumn{3}{|l|}{ Diabetes } \\
\hline CAP & $24(36.4 \%)$ & $19(28.8 \%)$ \\
\hline Sepsis * & $97(46.0 \%)$ & $64(30.3 \%)$ \\
\hline \multicolumn{3}{|c|}{ Renal Disease } \\
\hline $\mathrm{CAP} *$ & $21(31.8 \%)$ & $7(10.6 \%)$ \\
\hline Sepsis * & $76(36.0 \%)$ & $46(21.8 \%)$ \\
\hline \multicolumn{3}{|c|}{ Peripheral Vascular } \\
\hline CAP & $13(19.7 \%)$ & $9(13.6 \%)$ \\
\hline Sepsis & $61(28.9 \%)$ & $45(21.3 \%)$ \\
\hline \multicolumn{3}{|c|}{$25(\mathrm{OH}) \mathrm{D}(\mathrm{nmol} / \mathrm{L}) * *$} \\
\hline CAP & $70.1[62.2-79.6]$ & $79.3[71.1-88.1]$ \\
\hline Sepsis & $61.2[55.9-66.4]$ & $69.1[64.2-74.1]$ \\
\hline
\end{tabular}


Table 1. Cont.

\begin{tabular}{|c|c|c|}
\hline \multicolumn{3}{|c|}{$25(\mathrm{OH}) \mathrm{D}>75 \mathrm{nmol} / \mathrm{L}$} \\
\hline CAP & $34(52.3 \%)$ & $35(53.0 \%)$ \\
\hline Sepsis & $84(39.8 \%)$ & $99(46.9 \%)$ \\
\hline \multicolumn{3}{|c|}{ 25(OH)D 51-75 nmol/L } \\
\hline CAP & $19(28.8 \%)$ & $19(28.8 \%)$ \\
\hline Sepsis & $56(26.5 \%)$ & $60(28.4 \%)$ \\
\hline \multicolumn{3}{|c|}{ 25(OH)D 37-50 nmol/L } \\
\hline CAP & $7(10.6 \%)$ & $10(15.2 \%)$ \\
\hline Sepsis & $31(14.7 \%)$ & $29(13.7 \%)$ \\
\hline \multicolumn{3}{|c|}{$25(\mathrm{OH}) \mathrm{D}<37 \mathrm{nmol} / \mathrm{L}$} \\
\hline CAP & $9(9.1 \%)$ & $2(3.0 \%)$ \\
\hline Sepsis * & $40(19.0 \%)$ & $23(10.9 \%)$ \\
\hline
\end{tabular}

In unadjusted logistic regression, log-transformed $25(\mathrm{OH}) \mathrm{D}$ as a continuous variable was not associated with CAP (0.99 [0.90-1.09], $p=0.84)$. A lack of association remained after adjustment for diabetes, renal disease, and peripheral vascular disease (OR 0.94 [0.59-1.48], $p=0.78$ ). Likewise, $25(\mathrm{OH}) \mathrm{D}<75 \mathrm{nmol} / \mathrm{L} v s . \geq 75 \mathrm{nmol} / \mathrm{L}$ and $<50 \mathrm{nmol} / \mathrm{L} v s . \geq 50 \mathrm{nmol} / \mathrm{L}$ were not associated with CAP in adjusted analyses (Table 2). However, when $25(\mathrm{OH}) \mathrm{D}$ was categorized as $<37 \mathrm{nmol} / \mathrm{L} v s . \geq 37 \mathrm{nmol} / \mathrm{L}$, there was an association with increased odds of CAP (OR 2.57 [1.08-6.08], $p=0.03$; Table 2) in the adjusted model.

Table 2. Adjusted odds ratios for Community-Acquired Pneumonia (CAP) and Sepsis Cases relative to controls by serum $25(\mathrm{OH}) \mathrm{D}$ levels.

\begin{tabular}{|c|c|c|}
\hline Model ${ }^{\S}$ & OR $(95 \% \mathrm{CI})$ & $p$-Value \\
\hline \multicolumn{3}{|c|}{$25(\mathrm{OH}) \mathrm{D}<75 \mathrm{nmol} / \mathrm{L} v \mathrm{~s} . \geq 75 \mathrm{nmol} / \mathrm{L}$} \\
\hline CAP & $1.03(0.51-2.09)$ & 0.93 \\
\hline Sepsis & $1.24(0.84-1.83)$ & 0.28 \\
\hline \multicolumn{3}{|c|}{$25(\mathrm{OH}) \mathrm{D}<50 \mathrm{nmol} / \mathrm{L} v \mathrm{ss} . \geq 50 \mathrm{nmol} / \mathrm{L}$} \\
\hline CAP & $0.96(0.35-2.61)$ & 0.94 \\
\hline Sepsis & $1.75(1.11-2.77)$ & 0.02 \\
\hline \multicolumn{3}{|c|}{$25(\mathrm{OH}) \mathrm{D}<37 \mathrm{nmol} / \mathrm{L} v s . \geq 37 \mathrm{nmol} / \mathrm{L}$} \\
\hline CAP & $2.57(1.08-6.08)$ & 0.03 \\
\hline Sepsis & $1.89(1.09-3.31)$ & 0.02 \\
\hline
\end{tabular}

$\S$ Adjustments made for diabetes, renal disease, peripheral vascular disease; CAP, community-acquired pneumonia; 25(OH)D, 25 hydroxyvitamin D.

\subsection{Sepsis}

The demographic and clinical characteristics of the 211 cases and 211 controls for the sepsis cohort are described in Table 1. The mean (SD) age of the participants was $65 \pm 14$ years, $59 \%$ were female and $91 \%$ were Caucasian. There was no statistically significant difference in median [IQR] 25(OH)D levels in controls $v s$. cases $(69.1[64.2-74.1] \mathrm{nmol} / \mathrm{L} v s$. $61.2[55.9-66.4] \mathrm{nmol} / \mathrm{L}, p=0.05)$. 
Comorbid conditions were more prevalent in sepsis cases than in controls: diabetes $(46.0 \% \mathrm{vs} .30 .3 \%$, $p=0.0009)$ and renal disease $(36.0 \%$ vs. $21.2 \%, p=0.001)$. Serum 25(OH)D levels were recorded in 93 cases 3-5 months prior, in 50 cases 6-11 months prior, in 47 cases $9-11$ months prior, and 21 cases 12-15 months prior to admission.

In unadjusted logistic regression, log-transformed $25(\mathrm{OH}) \mathrm{D}$ as a continuous variable was not associated with sepsis (OR 0.99 [0.93-1.05], $p=0.70$ ). A lack of association remained after adjustment for diabetes, renal disease, and peripheral vascular disease (OR 0.82 [0.64-1.05], $p=0.12$ ). $25(\mathrm{OH}) \mathrm{D}<75 \mathrm{nmol} / \mathrm{L} v s . \geq 75 \mathrm{nmol} / \mathrm{L}$ was not associated with sepsis in adjusted analyses (Table 2). However, when $25(\mathrm{OH}) \mathrm{D}$ was categorized as $<50 \mathrm{nmol} / \mathrm{L} \quad v s . \geq 50 \mathrm{nmol} / \mathrm{L}$ and $<37 \mathrm{nmol} / \mathrm{L}$ $v s . \geq 37 \mathrm{nmol} / \mathrm{L}$, there was an association with increased odds of sepsis (Table 2, OR 1.75 [1.11-2.77], $p=0.02$ and 1.89 [1.09-3.31], $p=0.02$, respectively) in adjusted analyses.

\section{Discussion}

In a cohort of community-living adults, increased risk of hospitalization for CAP was associated with serum 25(OH)D levels $<37 \mathrm{nmol} / \mathrm{L}$ and for sepsis with serum $25(\mathrm{OH}) \mathrm{D}$ levels $<50 \mathrm{nmol} / \mathrm{L}$. This association was not observed for $25(\mathrm{OH}) \mathrm{D}<75 \mathrm{nmol} / \mathrm{L}$, suggesting that $25(\mathrm{OH}) \mathrm{D}<37 \mathrm{nmol} / \mathrm{L}$ confers a greater risk of infection than vitamin $\mathrm{D}$ insufficiency.

These findings are consistent with other epidemiologic studies linking vitamin D deficiency with increased risk of infection and infection-associated complications. A large observational study using National Health and Nutrition Examination Survey data showed that in a diverse cohort of 18,883 individuals greater than 12 years of age, those with a serum $25(\mathrm{OH}) \mathrm{D}$ level $<25 \mathrm{nmol} / \mathrm{L}$ and a serum $25(\mathrm{OH}) \mathrm{D} 25-75 \mathrm{nmol} / \mathrm{L}$ had a $36 \%$ and $24 \%$ increased risk of upper respiratory tract infection, respectively, compared to those with a serum $25(\mathrm{OH}) \mathrm{D} \geq 75 \mathrm{nmol} / \mathrm{L}$ [11]. Likewise, in a prospective observational study evaluating 25(OH)D levels in Finnish military recruits, $25(\mathrm{OH}) \mathrm{D}$ levels $<40 \mathrm{nmol} / \mathrm{L}$ were associated with a higher likelihood of physician diagnosed respiratory tract infections and lost days of work in the subsequent six months [13]. Ginde and colleagues reported that upon presentation to an urban emergency department, 81 patients with sepsis and $25(\mathrm{OH}) \mathrm{D}$ levels $<75 \mathrm{nmol} / \mathrm{L}$ were more likely to have severe sepsis compared to those with $25(\mathrm{OH}) \mathrm{D}$ levels $\geq 75 \mathrm{nmol} / \mathrm{L}(61 \%$ vs. $24 \%$, $p=0.006)$ at initial evaluation and at $24 \mathrm{~h}(67 \%$ vs. $29 \%, p=0.005)$ [15]. While other studies have measured 25(OH)D levels at acute illness onset, our study evaluates 25(OH)D levels at least 3 months prior to hospital admission, thus suggesting that there is an increased risk of CAP with a $25(\mathrm{OH}) \mathrm{D}$ level $<37 \mathrm{nmol} / \mathrm{L}$ and sepsis with a $25(\mathrm{OH}) \mathrm{D}$ level $<50 \mathrm{nmol} / \mathrm{L}$. It also eliminates the potential for confounding by acute illness altering serum 25(OH)D levels.

Both the VDR and CYP27B1, the gene encoding 1- $\alpha$-hydroxylase, which converts $25(\mathrm{OH}) \mathrm{D}$ to its active form $1,25(\mathrm{OH})_{2} \mathrm{D}$, are expressed in immune cells, suggesting that $25(\mathrm{OH}) \mathrm{D}$ has paracrine or autocrine function. Furthermore, 1- $\alpha$-hydroxylase in macrophages is not regulated by parathyroid hormone $(\mathrm{PTH})$ [22] but depends on circulating 25(OH)D concentrations or may be induced by cytokines [23]. When toll-like receptors on macrophages bind bacterial wall lipopolysaccharides (LPS), 1- $\alpha$-hydroxylase and VDR expression is increased ${ }^{4}$ resulting in local conversion of $25(\mathrm{OH}) \mathrm{D}$ to $1,25(\mathrm{OH})_{2} \mathrm{D}$, which in turn increases the expression of cathelicidin and beta-defensing, bactericidal proteins. There is evidence that cathelicidin transcription is particularly dependent on sufficient levels 
of 25(OH)D [4]. Indeed, in a study of critically ill patients with and without sepsis, Jeng and colleagues report a positive relationship between $25(\mathrm{OH}) \mathrm{D}$ levels and LL-37 (cathelicidin) levels [24].

In sepsis, $25(\mathrm{OH}) \mathrm{D}$ and $1,25(\mathrm{OH})_{2} \mathrm{D}$ may have other effects beyond those associated with immunity such as endothelial function, coagulation, and hemodynamic stability. In rats with induced sepsis, pretreatment with $1,25(\mathrm{OH})_{2} \mathrm{D}$ resulted in a more normal coagulation profile compared to placebo [25]. The VDR is also found in arterioles and the myocardium [26] and $1,25(\mathrm{OH})_{2} \mathrm{D}$ has been shown to enhance the effect of inotropes [27] suggesting a possible positive hemodynamic effect of $1,25(\mathrm{OH})_{2} \mathrm{D}$ in sepsis [25]. Taken together, sufficient circulating $25(\mathrm{OH}) \mathrm{D}$ levels, independent of the classic vitamin D-PTH axis, play a pivotal role in immunity. Moreover, $25(\mathrm{OH}) \mathrm{D}$ may also be protective against the adverse physiologic changes that occur in sepsis.

The findings of this study are consistent with other epidemiologic reports linking serum $25(\mathrm{OH}) \mathrm{D}<75 \mathrm{nmol} / \mathrm{L}$ with increased risk of infection and associated complications [11-16]. While other studies measured $25(\mathrm{OH}) \mathrm{D}$ levels during acute illness, this is the first to evaluate $25(\mathrm{OH}) \mathrm{D}$ levels $\geq 3$ months prior to hospital admission for CAP or sepsis, eliminating potential confounding by acute illness altering serum $25(\mathrm{OH}) \mathrm{D}$ levels. This study has important strengths. Chest radiograph confirmed CAP ICD-9 codes. Serum 25(OH)D level was measured prior to the onset of illness, which is different from other studies that measured $25(\mathrm{OH}) \mathrm{D}$ at the time of presentation. This is important because vitamin $\mathrm{D}$ binding protein may be decreased resulting in potential urinary wasting of $25(\mathrm{OH}) \mathrm{D}$ in sepsis [24]. Finally, this study used a community-living cohort that included a relatively large number of patients with sepsis.

This study has several limitations. First, it is retrospective and observational so causation cannot be assumed. Second, the use of ICD-9 codes to identify admissions for sepsis limits details of cause and severity. Third, while cases and controls were well-matched and regression models adjusted for comorbidities, there may be other unmeasured confounders that could potentially affect the results. Fourth, ascertainment bias may exist because only cases and controls with a serum $25(\mathrm{OH}) \mathrm{D}$ level available prior to admission were considered. Additionally, no information is available on outcomes during the hospitalization.

\section{Conclusions}

In conclusion, serum $25(\mathrm{OH}) \mathrm{D}$ level $<37 \mathrm{nmol} / \mathrm{L}$ in a community-living cohort was associated with increased risk of hospital admission for CAP and sepsis. Large randomized controlled trials are needed to establish whether or not $25(\mathrm{OH}) \mathrm{D}$ repletion will decrease CAP and sepsis incidence in community-living adult populations.

\section{Acknowledgments}

This work was supported by the National Institute of Health and the American Geriatrics Society Beeson Career Development Award [grant number K23AG040708] and the American Geriatrics Society Jahnigen Career Development Scholars Award to AG; the National Institute of Diabetes and Digestive and Kidney Diseases [grant numbers 1R01DK081473-01A, 1R01DK078112-01A2] to MC; the National Institute of Diabetes and Digestive and Kidney Diseases [grant number K23DK087859-01A1] to JK. 


\section{Author Contributions}

Anna Jovanovich, John Holmen, Jessica Kendrick and Michel Chonchol had full access to all of the data in the study and take responsibility for the integrity of the data and the accuracy of the data analysis. Study concept and design: Jovanovich, Ginde, Holmen, Jablonski, ALlyn, Kendrick and Chonchol. Collection, management, analysis and interpretation of data: Jovanovich, Ginde, Holmen, Jablonski, Allyn, Kendrick and Chonchol. Preparation, review, or approval of manuscript: Jovanovich, Ginde, Holmen, Jablonski, Allyn, Kendrick and Chonchol.

\section{Conflicts of Interest}

The authors declare no conflict of interest.

\section{References}

1. Mandell, L.A.; Wunderink, R.G.; Anzueto, A.; Bartlett, J.G.; Campbell, G.D.; Dean, N.C.; Dowell, S.F.; File, T.M., Jr.; Musher, D.M.; Niederman, M.S.; et al. Infectious Diseases Society of America/American Thoracic Society consensus guidelines on the management of community-acquired pneumonia in adults. Clin. Infect. Dis. 2007, 44, S27-S72.

2. Deaths: Preliminary Data for 2009. National Vital Statistics Reports. CDC. 2011. Available online: http://www.cdc.gov/nchs/data/nvsr/nvsr59/nvsr59_04.pdf (accessed on 16 March 2011).

3. Martin, G.S.; Mannino, D.M.; Eaton, S.; Moss, M. The epidemiology of sepsis in the United States from 1979 through 2000. N. Engl. J. Med. 2003, 348, 1546-1554.

4. Liu, P.T.; Stenger, S.; Li, H.; Wenzel, L.; Tan, B.H.; Krutzik, S.R.; Ochoa, M.T.; Schauber, J.; $\mathrm{Wu}, \mathrm{K}$; Meinken, C.; et al. Toll-like receptor triggering of a vitamin D-mediated human antimicrobial response. Science 2006, 311, 1770-1773.

5. White, J.H. Vitamin D metabolism and signaling in the human immune system. Rev. Endocr. Metab. Disord. 2012, 13, 21-29.

6. Ginde, A.A.; Liu, M.C.; Camargo, C.A., Jr. Demographic differences and trends of vitamin D insufficiency in the US population, 1988-2004. Arch. Intern. Med. 2009, 169, 626-632.

7. Holick, M.F. Vitamin D for health and in chronic kidney disease. Semin. Dial. 2005, 18, 266-275.

8. Scragg, R.; Sowers, M.; Bell, C.; Third National Health and Nutrition Examination Survey. Serum 25-hydroxyvitamin D, diabetes, and ethnicity in the Third National Health and Nutrition Examination Survey. Diabetes Care 2004, 27, 2813-2818.

9. Chonchol, M.; Scragg, R. 25-Hydroxyvitamin D, insulin resistance, and kidney function in the Third National Health and Nutrition Examination Survey. Kidney Int. 2007, 71, 134-139.

10. Melamed, M.L.; Muntner, P.; Michos, E.D.; Uribarri, J.; Weber, C.; Sharma, J.; Raggi, P. Serum 25-hydroxyvitamin D levels and the prevalence of peripheral arterial disease: Results from NHANES 2001 to 2004. Arterioscler. Thromb. Vasc. Biol. 2008, 28, 1179-1185.

11. Ginde, A.A.; Mansbach, H.M.; Camargo, C.A., Jr. Association between serum 25-hydroxyvitamin D level and upper respiratory tract infection in the Third National Health and Nutrition Examination Survey. Arch. Intern. Med. 2009, 169, 384-390. 
12. Sabetta, J.R.; DePetrillo, P.; Cipriani, R.J.; Smardin, J.; Burns, L.A.; Landry, M.L. Serum 25-hydroxyvitamin $\mathrm{D}$ and the incidence of acute viral respiratory tract infection in healthy adults. PLoS One 2010, 5, e11088.

13. Laaksi, I.; Ruohola, J.P.; Tuohimaa, P.; Auvinen, A.; Haataja, R.; Pihajamaki, H.; Ylikomi, T. An association of serum vitamin $\mathrm{D}$ concentrations $<40 \mathrm{nmol} / \mathrm{L}$ with acute respiratory tract infection in young Finnish men. Am. J. Clin. Nutr. 2007, 86, 714-717.

14. Leow, L.; Simpson, T.; Cursons, R.; Karalus, N.; Hancox, R.J. Vitamin D, innate immunity and outcomes in community acquired pneumonia. Respirology 2011, 16, 611-616.

15. Ginde, A.A.; Camargo, C.A., Jr.; Shapiro, N.I. Vitamin D insufficiency and sepsis severity in emergency department patients with suspected infection. Acad. Emerg. Med. 2011, 18, 551-554.

16. Braun, A.B.; Gibbons, F.K.; Litonjua, A.A.; Giovannucci, E.; Christopher, K.B. Low serum 25-hydroxyvitamin D at critical care initiation is associated with increased mortality. Crit. Care Med. 2012, 40, 63-72.

17. Intermoutain Healthcare Annual Report. Intermountain Healthcare 2010. Available online: http://intermountainhealthcare.org/about/overview/Documents/annualreport2010.pdf (accessed on 12 December 2012).

18. Mehrotra, R.; Kermah, D.A.; Salusky, I.B.; Wolf, M.S.; Thadhani, R.I.; Chiu, Y.W.; Martins, D.; Adler, S.G.; Norris, K.C. Chronic kidney disease, hypovitaminosis D, and mortality in the United States. Kidney Int. 2009, 76, 977-983.

19. Institute of Medicine. Dietary References Intakes for Calcium and Vitamin D. Available online: http://www.iom.edu/Activities/Nutrition/DRIVitDCalcium/2010-Nov-30.aspx (accessed on 12 December 2012).

20. Anderson, J.L.; May, H.T.; Horne, B.D.; Bair, T.L.; Hall, N.L.; Carlquist, J.F.; Lappé, D.L.; Muhlestein, J.B.; Intermountain Heart Collaborative (IHC) Study Group. Relation of vitamin d deficiency to cardiovascular risk factors, disease status, and incident events in a general healthcare population. Am. J. Cardiol. 2010, 106, 953-958.

21. Sterling, K.A.; Eftekhari, P.; Girndt, M.; Kimmel, P.L.; Raj, D.S. The immunoregulatory function of vitamin D: Implications in chronic kidney disease. Nat. Rev. Nephrol. 2012, 8, 403-412.

22. Wu, S.; Ren, S.; Nguyen, L.; Adams, J.S.; Hewison, M. Splice variants of the CYP27b1 gene and the regulation of 1,25-dihydroxyvitamin D3 production. Endocrinology 2007, 148, 3410-4318.

23. Van Etten, E.; Stoffels, K.; Gysemans, C.; Mathieu, C.; Overbergh, L. Regulation of vitamin D homeostasis: Implications for the immune system. Nutr. Rev. 2008, 66, S125-S134.

24. Jeng, L.; Yamshchikov, A.V.; Judd, S.E.; Blumberg, H.M.; Martin, G.S.; Ziegler, T.R.; Tangpricha, V. Alterations in vitamin D status and anti-microbial peptide levels in patients in the intensive care unit with sepsis. J. Transl. Med. 2009, 7, 28.

25. Moller, S.; Laigaard, F.; Olgaard, K.; Hemmingsen, C. Effect of 1,25-dihydroxy-vitamin $\mathrm{D}_{3}$ in experimental sepsis. Int. J. Med. Sci. 2007, 4, 190-195.

26. Bukoski, R.D.; Xue, H. On the vascular inotropic action of 1,25-(OH)2 vitamin D3. Am. J. Hypertens. 1993, 6, 388-396. 
27. Walters, M.R.; Wicker, D.C.; Riggle, P.C. 1,25-Dihydroxyvitamin D3 receptors identified in the rat heart. J. Mol. Cell. Cardiol. 1986, 18, 67-72.

(C) 2014 by the authors; licensee MDPI, Basel, Switzerland. This article is an open access article distributed under the terms and conditions of the Creative Commons Attribution license (http://creativecommons.org/licenses/by/3.0/). 